\title{
The impact of CLAUDIN-1 on follicular thyroid carcinoma aggressiveness
}

\author{
Denise Zwanziger, ${ }^{1, *}$, Julia Badziong, ${ }^{1, *}$, Saskia Ting ${ }^{2}$, Lars Christian Moeller', \\ Kurt Werner Schmid ${ }^{2}$, Udo Siebolts ${ }^{3}$, Claudia Wickenhauser ${ }^{3}$, Henning Dralle ${ }^{4}$ and \\ Dagmar Fuehrer ${ }^{1}$
}

${ }^{1}$ Department of Endocrinology and Metabolism, University Hospital Essen, and ${ }^{2}$ Institute of Pathology, University Hospital Essen, Hufelandstraße 55, 45147 Essen, Germany

${ }^{3}$ Department of Pathology, University Hospital Halle, Magdeburger Straße 14, 06097 Halle, Germany

${ }^{4}$ Department of General-, Visceral- and Vascular Surgery, University Hospital Halle, Ernst-Grube-Straße 40, 06120 Halle, Germany

*(D Zwanziger and J Badziong contributed equally to this work)

\begin{abstract}
CLAUDIN-1 belongs to the family of transmembrane tight junction proteins tightening the paracellular cleft of epithelial cells. In human malignancies, CLAUDIN-1 is often dysregulated and located in subcellular compartments, particularly in the nucleus where it may influence cellular behaviour. Here, we studied CLAUDIN-1 in relation to the biological characteristics of follicular thyroid carcinoma (FTC). CLAUDIN-1 immuno-staining showed loss of membrane expression and increased nuclear CLAUDIN-1 localization in FTC metastases. CLAUDIN-1 function was further investigated in two different follicular thyroid carcinoma cell lines: FTC-133 isolated from a regional lymph node metastasis and FTC-238 derived from a lung metastasis. In both cell lines CLAUDIN-1 expression was demonstrated in the cell nuclei with a significantly higher protein expression in FTC-238 compared to FTC-133 cells. Interestingly, in vitro scratch assay revealed enriched nuclear CLAUDIN-1 expression near the scratch. Furthermore, the increase of the pathogenic character of FTC-133 cells by RASV12 transfection was associated with elevated CLAUDIN-1 expression and enhanced cell migration, invasion and proliferation. Likewise over-expression of nuclear CLAUDIN-1 in FTC-133 cells resulted in increased cell migration and invasion. Conversely, CLAUDIN-1 downregulation in FTC-238 cells by siRNA resulted in decreased cell migration and invasion and was accompanied by reduced phosphoPKC expression. Moreover, activation and inhibition of PKC resulted in CLAUDIN-1 up- and downregulation in FTC cells respectively. These data suggest an impact of CLAUDIN-1 on follicular thyroid carcinoma aggressiveness, which could potentially be influenced by PKC activity.
\end{abstract}

Correspondence should be addressed to D Zwanziger Email denise.zwanziger@ uk-essen.de

\section{Introduction}

Thyroid cancer is the most common form of endocrine malignancies. Follicular thyroid carcinoma (FTC) has an incidence of $15-20 \%$ and is the second most frequent thyroid carcinoma (Ban et al. 2012). If FTC disseminates, it typically shows a haematogenic metastasizing pattern, predominantly with lung and bone metastases 
(Muresan et al. 2008). Characteristic genetic alterations found in FTC include mutations in the rat sarcoma $(\mathrm{H}-, \mathrm{K}-$, $N$-RAS) genes or paired box gene 8/peroxisome proliferator-activated receptor gamma $(P A X 8 / P P A R \gamma)$ rearrangements leading to constitutive activation of signal cascades like MAPK/ERK, PI3K/AKT or Wnt (McIver et al. 2004, Theoharis et al. 2012). However, the precise mechanisms of follicular thyroid carcinogenesis and reasons for metastases are not well understood and therefore remain an important issue in thyroid cancer research.

CLAUDIN proteins belong to the family of transmembrane tight junction proteins and are key regulators in the sealing of the paracellular cleft of epithelial and endothelial cells. From the currently known 27 CLAUDIN members, CLAUDIN-1 is assumed to be the most important protein responsible for the paracellular barrier integrity of epithelial cells (Gonzalez-Mariscal et al. 2003). In tumor progression, tight junction assembly is often disrupted resulting in the loss of cell membrane localized tight junction proteins (Resnick et al. 2005, Tokes et al. 2005). For CLAUDIN-1, an altered protein expression as well as subcellular localization has been observed in common human malignancies including colon, lung and breast cancer and melanoma (Tokes et al. 2005, Chao et al. 2009, Nemeth et al. 2010). Furthermore, subcellular CLAUDIN-1 expression has been associated with a more aggressive tumour behaviour (Miwa et al. 2001). Alterations in different CLAUDIN subtypes have also been described in human thyroid cancer tissues (Tzelepi et al. 2008), whereby a weak subcellular expression of CLAUDIN-1 in FTC was reported to correlate with disease recurrence and survival. However, the mechanism behind the possible impact of CLAUDIN1 on FTC biology was not addressed. In this study we investigated CLAUDIN-1 expression and localization in a series of follicular adenoma, FTC primary tumours and FTC metastases as well as normal thyroid tissues. We found increased subcellular CLAUDIN-1 expression in follicular thyroid tumours and nuclear CLAUDIN-1 localization in FTC metastases. In addition, functional properties of CLAUDIN-1 were investigated in two human follicular thyroid carcinoma cell lines: FTC-133 and FTC-238. These cell lines originate from a 42-yearold patient with follicular thyroid carcinoma (Hoelting et al. 1994). The FTC-133 cells are derived from a regional lymph node metastasis, whereas the FTC-238 cells are derived from a lung metastasis. Therefore, these cell lines are at present suitable in vitro tools to study tumour aggressiveness of human follicular thyroid carcinoma. We modulated the pathogenic character of these cell lines with respect to CLAUDIN-1 expression and/or protein kinase $\mathrm{C}$ (PKC) activity and characterized them for functional properties by addressing migration, invasion and proliferation.

\section{Materials and methods}

\section{Thyroid samples}

Thyroid samples were obtained from patients undergoing thyroid surgery for nodular thyroid disease or thyroid cancer. For immunohistochemical analysis of CLAUDIN-1, paraffin-embedded tissue sections of 40 follicular adenoma, 44 follicular thyroid carcinoma and six distant metastases of follicular thyroid carcinoma (soft tissue and liver metastases) and normal surrounding thyroid tissues were studied. Classification of the thyroid nodules was performed by the pathologists according to World Health Organization (WHO) criteria.

\section{Immunohistochemistry}

Paraffin-embedded tissue sections were incubated with an anti-claudin-1 antibody (1:100, Invitrogen, 71-7800). Immuno-reactivity was demonstrated using biotinylated secondary anti-mouse antibody, streptavidin peroxidase and diaminobenzidine. Sections were counterstained with hemalaun and mounted in Aquatex (Merck, Darmstadt, Germany). Paraffin-embedded skin tissue sections were used as positive control. Negative control, without anticlaudin-1 antibody, was included in the experimental setup. All samples were viewed on the Olympus BX51 upright microscope (Olympus). Staining intensities were evaluated by calculating the hybrid $(\mathrm{H})$ score of membrane, cytoplasmic and nuclear CLAUDIN-1 expression.

\section{Cell culture}

The following human follicular thyroid carcinoma cell lines were used: FTC-133 and FTC-238 (Hoelting et al. 1994). Both FTC cell lines are derived from the same male patient and present a homozygous p53 activating mutation, whereas a homozygous phosphatase and tensin homolog inactivating mutation is only present in FTC-133 cells (Simon et al. 1994, Saiselet et al. 2012). FTC cell lines were purchased from the European Collection of Cell Cultures (ECACC, Salisbury, UK) and were re-authenticated by the mRNA expression profile of thyroid hormone markers and negatively analysed for mycoplasma contamination (AppliChem GmbH, Darmstadt, Germany).

Published by Bioscientifica Ltd 
Cells were used between passages 5 and 15. Follicular thyroid carcinoma cells were cultured in Ham's F12 Nutrient Mixture (Invitrogen) containing 10\% FCS (Invitrogen) and 1\% ZellShield (Minerva Biolabs, Berlin, Germany). For migration and invasion studies, cells were cultured in serum-low medium containing Ham's F12 Nutrient Mixture with 2\% FCS and 1\% ZellShield. Cells were grown at $37^{\circ} \mathrm{C}$ and $5 \% \mathrm{CO}_{2}$.

\section{Transfection procedure}

The pcDNA3.1 H-RASV12C40 and the peYFP Cld1-C2 plasmids were kindly provided by Dr K Krause (Leipzig, Germany) and PD Dr I E Blasig (Berlin, Germany) respectively. The pcDNA3.1 RASV12 plasmid was generated by site-directed mutagenesis using the Quikchange II site-directed mutagenesis kit (Stratagene, La Jolla, CA, USA) to re-mutate the cytosine in position 40 into a guanine. The peYFP Cld1-C2 plasmid was restricted by BamHI and HindIII (Fermentas, Waltham, MA, USA). Ligation of Cld1 and pcDNA3-YFP-NLS (NLS; nuclear localization sequence) was performed with T4-DNA-Ligase (NEB, Ipswich, MA, USA), and the product was transformed by heat-shock using One Shot Top 10 chemically competent cells (NEB). Grown colonies on lysogeny broth (LB)-agar plates were picked and grown in LB medium, and plasmid DNA was isolated using QIAprep Spin Miniprep Kit (Qiagen). For in frame location of Cld1, two mutagenesis steps using the Q5 site-directed mutagenesis kit (NEB) were performed. The correct sequences and orientations of the constructs were verified by DNA sequencing (Seqlab, Göttingen, Germany). The empty pcDNA3.1 and pcDNA3YFP-NLS vectors were used as control.

For transient transfection, FTC-133 cells were seeded onto poly-L-lysine (Sigma), collagen-I (Sigma) coated or non-coated 16 or $35 \mathrm{~mm}$ dishes and grown to $80 \%$ confluence for $48 \mathrm{~h}$. For each reaction in $35 \mathrm{~mm}$ dishes, a transfection cocktail containing $4 \mu \mathrm{g}$ DNA and $250 \mu \mathrm{l}$ OptiMEM (Invitrogen) as well as $10 \mu \mathrm{l}$ Lipofectamine 2000 (Invitrogen) and $250 \mu \mathrm{l}$ OptiMEM have been prepared and incubated at room temperature for $5 \mathrm{~min}$. Afterwards, the transfection cocktail was added to the cells and incubated for $16 \mathrm{~h}$ at $37^{\circ} \mathrm{C}$ and $5 \% \mathrm{CO}_{2}$. The medium was replaced by normal growth medium and cells were assayed $24-48 \mathrm{~h}$ post-transfection. For $16 \mathrm{~mm}$ dishes the adapted volume of transfection cocktail was used. Transfection efficiency was controlled by YFP fluorescence intensities of either Cld1 or empty vector (EV) transfection and ranged between 70 and $80 \%$.

\section{siRNA transfection}

Cells were plated in antibiotic-free normal growth medium on poly-L-lysine, collagen-I coated or non-coated, 16 or $35 \mathrm{~mm}$ dishes at $70-80 \%$ confluence for $48 \mathrm{~h}$. Solution mixes of claudin-1 siRNA $(10 \mu \mathrm{M})$ or nontargeting control siRNA $(10 \mu \mathrm{M})$ with siRNA transfection medium and siRNA transfection reagent (Santa Cruz) were prepared by following the procedure recommended by the manufacturers. Transfection cocktail was incubated at room temperature for $30 \mathrm{~min}$. Cells were washed once with siRNA transfection medium. Cells were incubated with transfection mixture for $6 \mathrm{~h}$ at $37^{\circ} \mathrm{C}$ and $5 \% \mathrm{CO}_{2}$. Normal growth medium containing $2 \times$ FCS was added and cells were incubated for $18 \mathrm{~h}$ at $37^{\circ} \mathrm{C}$ and $5 \% \mathrm{CO}_{2}$. The medium was aspirated and replaced by fresh normal growth medium and cells were incubated for $24 \mathrm{~h}$ at $37^{\circ} \mathrm{C}$ and $5 \% \mathrm{CO}_{2}$ before assayed.

\section{PKC activation by phorbol-12-myristate-13-acetate}

Cells were cultured in $35 \mathrm{~mm}$ dishes to confluent monolayers. Phorbol-12-myristate-13-acetate (PMA, Merck) was dissolved in DMSO (Sigma) and the corresponding growth medium to a final concentration of $200 \mathrm{nM}$. As control, cells were treated with equivalent amounts of DMSO (final DMSO <0.02\%). Cells were incubated for $6 \mathrm{~h}$ at $37{ }^{\circ} \mathrm{C}$ and $5 \% \mathrm{CO}_{2}$.

\section{PKC inhibition by Gö6983}

Cells were cultured in $35 \mathrm{~mm}$ dishes to confluent monolayers. Gö6983 (Sigma) was dissolved in DMSO and the corresponding growth medium to a final concentration of $100 \mathrm{nM}$. As control, cells were treated with equivalent amounts of DMSO (final DMSO $<0.02 \%$ ). Cells were incubated for $6 \mathrm{~h}$ at $37^{\circ} \mathrm{C}$ and $5 \% \mathrm{CO}_{2}$.

\section{Western blot}

The following antibodies were used: anti-claudin-1 (1:250, Invitrogen, 71-7800), anti-ß-actin (1:2000, Cell Signaling, Danvers, MA, USA), anti-RASV12 (1:200, Abcam, Berlin, Germany), anti-PKC (1:500, Sigma), anti-phosphoPKC (1:250, PromoKine, Heidelberg, Germany), anti-phosphop44/42 MAPK (1:1000, Cell Signaling), anti-phospho-AKT (1:1000, Cell Signaling) and anti-mouse/rabbit-IgG (1:2000, Cell Signaling). Whole protein lysates were extracted by RIPA-buffer (150 mM sodium chloride, $50 \mathrm{mM}$ Tris $\mathrm{pH}$ 8.0, $1 \%$ NP-40, $0.5 \%$ sodiumdeoxycholate, $0.1 \%$ sodium

Published by Bioscientifica Ltd. 
dodecyl sulfate, $2 \mathrm{mM}$ ethylenediaminetetraacetate, $50 \mathrm{mM}$ sodium fluoride, protease inhibitor (Sigma)). Extracted proteins were quantified by BCA protein assay (Pierce, Rockford, IL, USA). Aliquots of proteins (10-20 $\mu \mathrm{g}$ ) were fractionated on Any kD Criterion TGX SDS polyacrylamide gels (BioRad) and blotted by the Trans-Blot Turbo Transfer System (BioRad) onto PVDF membranes (Bio-Rad). Unspecific binding sites were blocked with blocking buffer (5\% milk powder in PBS (Sigma)) for $1 \mathrm{~h}$ at room temperature. Proteins were detected using the abovementioned antibodies by overnight incubation at $4{ }^{\circ} \mathrm{C}$ in blocking buffer. ß-actin was used as a protein loading control. Secondary antibody was incubated at room temperature for $2 \mathrm{~h}$. Visualization was done by luminescence using the Immun-Star WesternC Kit (BioRad). Differences in protein expression levels were quantified by densitometry using the Image Lab Software (BioRad). Relative values of either the loading control ß-actin or total PKC were calculated. The target protein values were divided by the calculated relative values of the respective control. The adjusted values were used to calculate the geometric mean of the controls and target protein followed by calculation of the percent of protein level alteration.

\section{Immunofluorescence}

The following antibodies were used: anti-claudin-1 (1:100, Invitrogen, 71-7800), AlexaFluor 555 Phalloidin (1:40, Invitrogen) and AlexaFluor 488 (1:200, Invitrogen) secondary antibody. Cells were seeded onto poly-L-lysine (Sigma) coated $16 \mathrm{~mm}$ cover slides. Cells were fixed in $4 \%$ paraformaldehyde (Sigma) for $15 \mathrm{~min}$ at room temperature and permeabilized using 0.1\% Triton X100 (Sigma) in PBS for $10 \mathrm{~min}$ at room temperature. The pre-incubation in blocking solution containing 3\% BSA and 0.3\% Triton X100 in PBS was performed at room temperature for $30 \mathrm{~min}$. Cells were incubated with primary antibodies overnight at $4{ }^{\circ} \mathrm{C}$ in PBS. Secondary antibody AlexaFluor 488 was incubated for $1 \mathrm{~h}$ at room temperature in PBS. The F-actin cytoskeleton was visualized by incubation of AlexaFluor 555 Phalloidin for $20 \mathrm{~min}$ at room temperature. The cell nuclei were stained by incubation of Hoechst 33342 (1:1000, Invitrogen) for $5 \mathrm{~min}$ at room temperature. Cover slides were embedded by ImmuMount (Thermo Scientific, Pittsburgh, PA, USA) and viewed on the confocal microscope Nikon Eclipse $T_{i}$.

\section{In vitro scratch assay}

For scratch assays, cells were seeded onto collagen-I coated $16 \mathrm{~mm}$ dishes and grown to confluence for $48 \mathrm{~h}$.
Transfection was performed as described above. Cells were incubated for $24 \mathrm{~h}$ in serum-low medium. The cell monolayer was cross-scraped by a pipette tip. In distinct time intervals the scratch was detected by a light microscope with camera system (Olympus CK40 with Olympus C5060 camera), amplification magnitude of $10 \times$. For analysis, TScratch Software has been used (Geback et al. 2009). The percentage of open scratch at the distinct time intervals has been normalized to the time point $0 \mathrm{~h}$ as $100 \%$ open scratch.

\section{Transwell migration assay}

Millicell Hanging Cell Culture Inserts (Millipore, Germany) were placed onto $16 \mathrm{~mm}$ dishes. The lower compartment contained $700 \mu$ normal growth medium. The upper compartment contained $200 \mu \mathrm{l}$ cells (35 000 cells $/ \mathrm{ml}$ ) in serum-low medium. Transwell migration was performed for $24 \mathrm{~h}$ at $37^{\circ} \mathrm{C}$ and $5 \% \mathrm{CO}_{2}$. The medium was replaced and non-migrated cells were removed by a cotton bud. Migrated cells were fixed with 100\% methanol (Sigma) for $2 \mathrm{~min}$ at room temperature and stained by $0.05 \%$ toluidine blue (Merck) in aqua bidest for $2 \mathrm{~min}$ at room temperature. After washing six times with aqua bidest, transwell filters were cut out and mounted in immersion oil (Merck). Analysis was performed by a light microscope with camera system (Olympus CK40 with Olympus C5060 camera) and a percentage of migrated cells per well normalized to the respective control was determined.

\section{Transwell invasion assay}

Millicell Hanging Cell Culture Inserts were placed onto $16 \mathrm{~mm}$ dishes and coated with Matrigel (200-300 $\mu \mathrm{g} / \mathrm{ml}$, BD Biosciences, San Jose, CA, USA) for $2 \mathrm{~h}$ at $37^{\circ} \mathrm{C}$. The lower compartment contained $700 \mu \mathrm{l}$ normal growth medium. The upper compartment contained $200 \mu \mathrm{l}$ cells (40 000 cells $/ \mathrm{ml}$ ) in serum-low medium. Transwell invasion was performed for $24 \mathrm{~h}$ at $37^{\circ} \mathrm{C}$ and $5 \% \mathrm{CO}_{2}$. The same protocol as described in transwell migration assay was used. The percentage of invaded cells/well normalized to the respective control was determined.

\section{Proliferation assay}

For proliferation assays, cells (10 000 cells/ml) were seeded onto $6 \mathrm{~mm}$ dishes and cultured at $37^{\circ} \mathrm{C}$ and $5 \% \mathrm{CO}_{2}$ for 24 h. 5-Bromo-2'-Deoxyuridine (BrdU) labelling solution (10 $\mu \mathrm{M}$, Roche, Germany) was incubated for $2 \mathrm{~h}$ at $37^{\circ} \mathrm{C}$

Published by Bioscientifica Ltd. 
and $5 \% \mathrm{CO}_{2}$. After washing once with $10 \times$ PBS, fixating with $70 \% \mathrm{EtOH} / 0.5 \mathrm{M} \mathrm{HCl}$ for $30 \mathrm{~min}$ at room temperature and washing three times with PBS/10\% FCS, nucleases were added for $30 \mathrm{~min}$ at $37^{\circ} \mathrm{C}$. Cells were washed three times, incubated with anti-BrdU-POD solution $(200 \mathrm{mU} / \mathrm{ml})$ for $30 \mathrm{~min}$ at $37^{\circ} \mathrm{C}$, again washed three times and incubated with peroxidase substrate for 2-30 $\mathrm{min}$ at room temperature before assayed by an ELISA reader (Molecular Devices, Sunyvale, CA, USA) at $405 \mathrm{~nm}$ and a reference wavelength of $490 \mathrm{~nm}$. The percentage of proliferating cells normalized to the respective control was determined.

\section{Statistical analysis}

For immunohistochemistry, the median H-score was determined. Cell culture experiments were performed in triplicates and repeated at least in $n=3-6$ independent experiments. Results are shown as mean \pm s.E.M. values obtained by $t$-test. Differences were considered significant if $P<0.05, P<0.01$ or $P<0.001$.

\section{Results}

\section{Cytoplasmic and nuclear CLAUDIN-1 localization in human follicular thyroid carcinoma tissues}

CLAUDIN-1 expression and localization was investigated in normal thyroid tissues, thyroid follicular adenomas, follicular thyroid cancers and FTC metastases (Fig. 1). In normal thyroid tissue, CLAUDIN-1 was expressed in the plasma membrane and cytoplasm. In follicular adenoma and primary FTC, CLAUDIN-1 staining was found in the plasma membrane and cytoplasm with few nuclear staining areas. In FTC metastases absent plasma membrane and increased nuclear CLAUDIN-1 expression was found (Fig. 1).

\section{CLAUDIN-1 expression is increased in FTC cells and correlates with metastatic potential}

The functional relevance of altered CLAUDIN-1 expression in follicular thyroid cancer was subsequently investigated in vitro. First, CLAUDIN-1 expression and localization was analysed by western blot and immunofluorescence in two follicular thyroid carcinoma cell lines FTC-133 and FTC-238, which represent distinct metastatic levels of the same primary FTC (Fig. 2A and B). CLAUDIN-1 was expressed in both cell lines but a $67 \%$ higher protein expression was seen in FTC-238, derived from a lung metastasis compared to FTC-133 cells, derived from a lymph node metastasis in
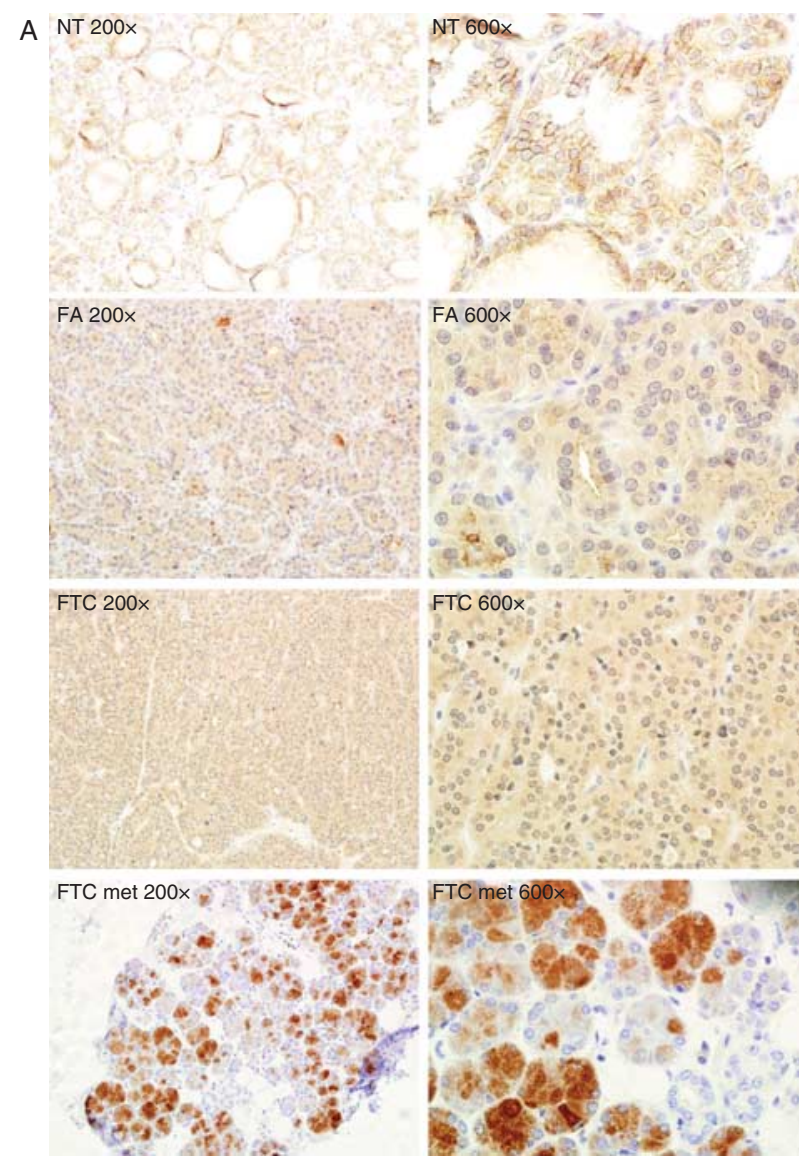

B

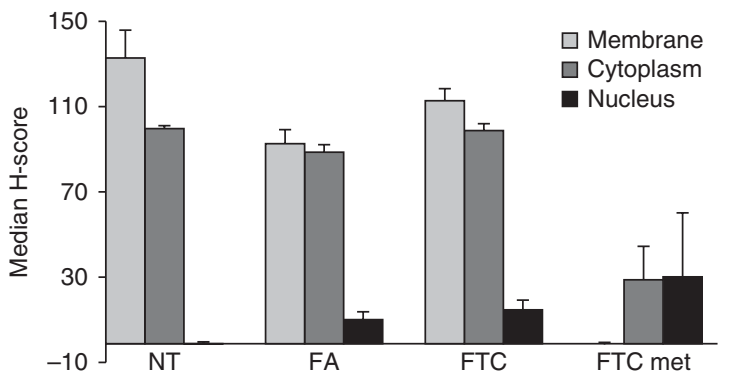

Figure 1

Immunohistochemical analysis of CLAUDIN-1 localization in normal thyroid tissues, follicular thyroid tumours and metastases of follicular thyroid cancer. (A) Normal thyroid tissue (NT) shows CLAUDIN-1 staining in the plasma membrane and cytoplasm. Decreased membrane CLAUDIN-1 expression was observed in follicular adenoma (FA) and follicular thyroid carcinoma (FTC). Soft tissue metastasis of FTC (FTC met) showing absent membrane and exclusive nuclear and cytoplasmic CLAUDIN-1 staining. Olympus BX51 upright microscope with a magnification of either $200 \times$ or $600 \times$. Representative examples are shown. (B) Semi-quantitative analysis of CLAUDIN-1 immuno-staining was performed for membrane, cytoplasm and nucleus localization by determining the median $\mathrm{H}$-score in normal thyroid tissues, 40 FA, 44 FTC and six FTC metastases. The median H-Score shows a trend for lower CLAUDIN-1 membrane immuno-reactivity in follicular tumours (FA and FTC) as well as absent membrane and increased nuclear CLAUDIN-1 expression in FTC metastases. A full colour version of this figure is available at http://dx.doi.org/10.1530/ERC-14-0502.

Published by Bioscientifica Ltd 
A

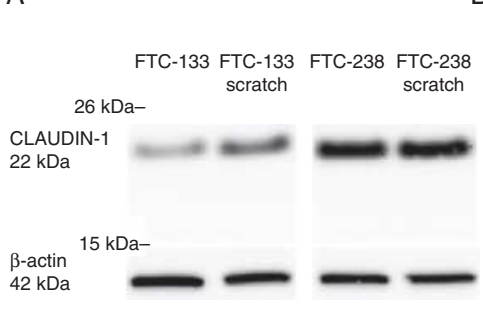

C
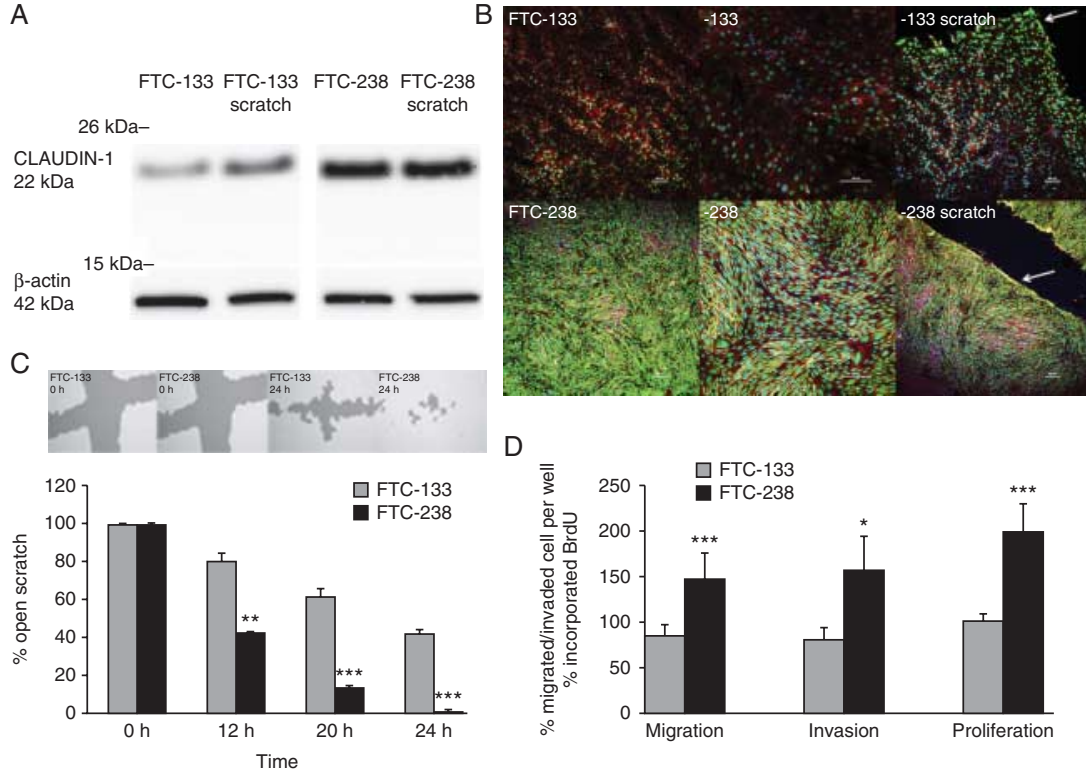

D

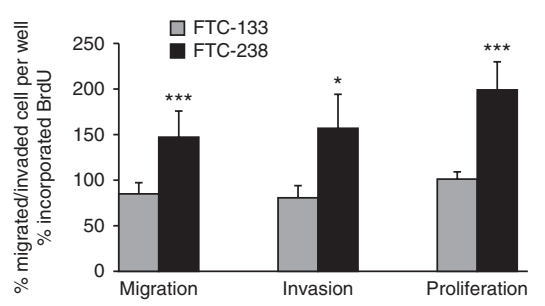

\section{Figure 2}

CLAUDIN-1 expression is increased in metastatic follicular thyroid carcinoma cells. (A) Protein expression of CLAUDIN-1 (22 kDa) in FTC-133 and FTC- 238 cells with and without scratch induction $(6 \mathrm{~h}$ post-scratch induction). Higher CLAUDIN-1 expression in FTC-238 as compared to FTC133 cells. Increase of CLAUDIN-1 expression during scratch closing process ( $6 \mathrm{~h}$ post-scratch induction). $\beta$-actin ( $42 \mathrm{kDa}$ ) was used as a loading control. (B) FTC cells with CLAUDIN-1 (green) protein expression in the cell nucleus and enhanced CLAUDIN-1 expression in FTC-238 as compared to FTC-133 cells. FTC-133 and FTC- 238 cells $6 \mathrm{~h}$ post-scratch induction with increased CLAUDIN-1 fluorescence signals around the scratch (arrow). F-actin cytoskeleton was stained by AlexaFluor 555 Phalloidin (red). Nuclei were stained by Hoechst33342 (cyan). Scale bar: $100 \mu \mathrm{m}$. Confocal microscope

proximity to the primary FTC (Fig. 2A). Both FTC-133 and FTC-238 cells exhibited CLAUDIN-1 expression mainly in the cell nucleus (Fig. 2B). On functional characterization, FTC-133 cells showed a slower cell migration, cell invasion and cell proliferation compared to FTC-238 cells (Fig. 2C and D). Likewise, in the scratch assay, FTC-133 cells showed a slower reconstitution of an intact cell monolayer compared to FTC-238 cells (Fig. 2C). Western blot analysis revealed an up to $15 \%$ increased CLAUDIN-1 expression in FTC-133 cells after scratching the cell monolayer (Fig. 2A). Interestingly, on immunofluorescence analysis, cells located close to the scratch showed higher CLAUDIN-1 fluorescence signals mainly in the nuclei as compared to cells in other areas of the cell monolayer (Fig. 2B). This applied for both FTC cell lines. Based on these findings, FTC-133 and FTC238 cells were selected as suitable in vitro models to further study the impact of CLAUDIN-1 in FTC aggressiveness.

To investigate if an increase of the pathogenic character of FTC-133 cells influences CLAUDIN-1 expression, a RASV12 mutation was introduced by transient transfection.
Nikon Eclipse $\mathrm{T}_{\mathrm{i}}$. Representative examples are shown $(n=3)$. (C) Faster closing of the scratch in FTC-238 than FTC-133 cells. Analysis was performed by TScratch Software (Computational Science \& Engineering Laboratory, ETH Zurich, Switzerland). The percentage of the open scratch at the distinct time intervals normalized to the respective control (time point at $0 \mathrm{~h}$ ) is shown. (D) Transwell migration, transwell invasion and cell proliferation rate of FTC cells. FTC-238 cells show a higher migration and invasion as well as proliferation rate as compared to FTC-133 cells. The percentage of migration, invasion or proliferation of cells/well normalized to the respective control is shown. Data are represented as mean \pm s.E.M., $n=3-6$, $t$-test, $* P<0.05, * * P<0.01$ and $* * * P<0.001$. A full colour version of this figure is available at http://dx.doi.org/10.1530/ERC-14-0502.

EV transfected FTC-133 cells were used as a negative control. In FTC-133+EV cells, no endogenous RASV12 expression was detected (Fig. 3A). In western blot analysis, FTC-133+ RASV12 cells showed a 35\% higher CLAUDIN-1 expression as compared to FTC-133+EV cells (Fig. 3A). In the scratch assay, FTC-133+RASV12 cells revealed a faster closing of the scratch than the control (Fig. 3B). A higher cell migration rate of FTC-133+RASV12 as compared to controls could also be demonstrated in the transwell migration assay (Fig. 3C). Furthermore, in the transwell invasion assay the FTC-133+RASV12 cells were more invasive than control cells (Fig. 3D) and a higher percentage of cells incorporating BrdU was found in line with the induction of cell proliferation (Fig. 3E).

\section{Nuclear CLAUDIN-1 modulation alters the aggressiveness of follicular thyroid carcinoma cells}

Next we asked if the modulation of nuclear CLAUDIN-1 expression in FTC cell lines alters their functional

Published by Bioscientifica Ltd 
A

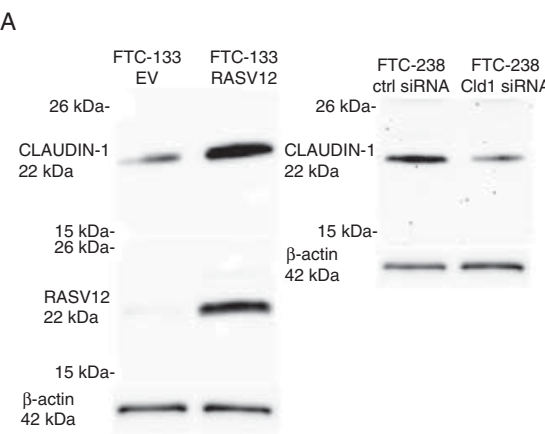

B
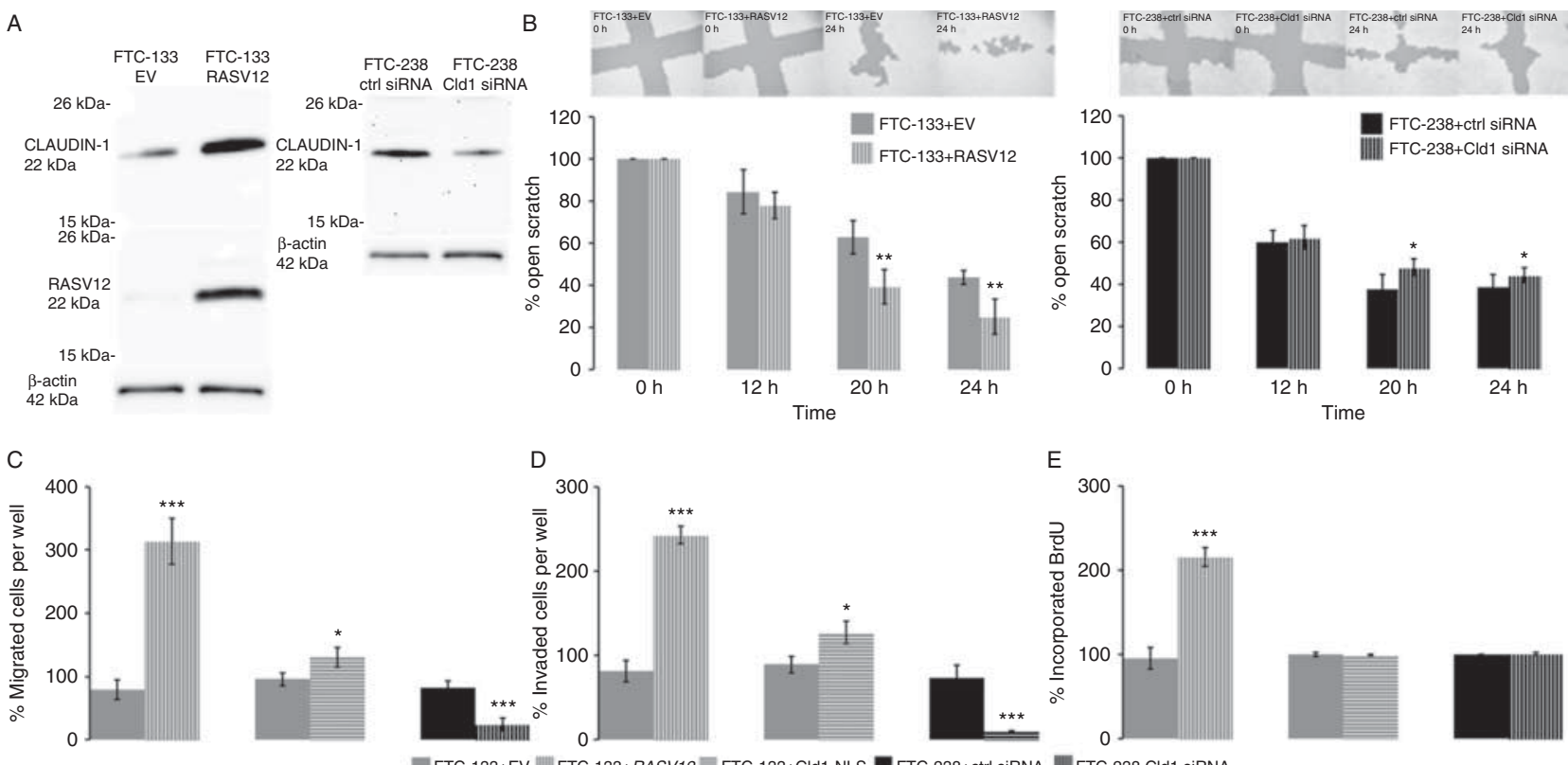

E
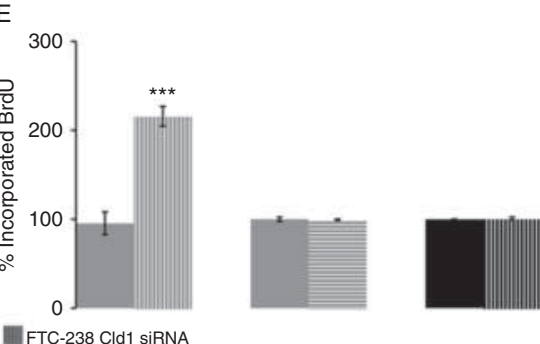

\section{Figure 3}

Modulation of CLAUDIN-1 expression alters the aggressiveness of follicular thyroid carcinoma cells. (A) Upregulation of CLAUDIN-1 by transient transfection of FTC-133 cells with RASV12 and downregulation of CLAUDIN-1 by Cld1 siRNA treatment of FTC-238 cells. EV transfected FTC133 cells and control (ctrl) siRNA-treated FTC-238 cells were used as controls. No endogenous RASV12 expression in EV transfected FTC-133 cells. Successful transfection was determined by RASV12 (21 kDa) protein expression. $\beta$-actin (42 kDa) was used as a loading control. (B) FTC-133+ RASV 12 cells show a significantly faster reconstitution of an intact cell monolayer as compared to controls. In contrast, FTC-238+Cld1 siRNA cells show a significantly decreased scratch closing rate compared to FTC-238+ ctrl siRNA cells. Non-targeting siRNA per se also slightly decreases the scratch closing capacity of FTC-238 cells. Analysis was performed by TScratch Software (Computational Science \& Engineering Laboratory, ETH

behaviour. Therefore, FTC-133 cells were transiently transfected with Cld1-NLS to over-express nuclear CLAUDIN-1, whereas in FTC-238 cells CLAUDIN-1 was downregulated by siRNA transfection. An EV or a non-targeting siRNA was used as negative controls. Positive transfection of Cld1-NLS was determined by fluorescence microscopy. Successful siRNA transfection of FTC-238 cells showing $44 \%$ downregulation of CLAUDIN-1 expression was determined by western blot analysis (Fig. 3A). In the scratch assay, a slower reconstitution of an intact cell monolayer was found for CLAUDIN-1 siRNA transfected FTC-238 cells as compared to the control (Fig. 3B). In fact, non-targeting control siRNA led to a slight decrease of scratch closing capacity in FTC-238 cells. In addition, a slower cell migration rate was found for CLAUDIN-1 siRNA transfected FTC-238 cells compared to the control in the transwell migration assay (Fig. 3C). Because of equal results obtained by scratch assay and transwell migration,
Zurich, Switzerland). The percentage of the open scratch at the distinct time intervals normalized to the respective control (at start of experiment, $0 \mathrm{~h}$ ) is shown. (C and D) FTC-133 + RASV12 and Cld1-NLS transfected FTC133 cells show a faster cell migration and invasion than the respective controls. In contrast, FTC-238+Cld1 siRNA cells reveal a slower cell migration and invasion as compared to controls. The percentage of migrated or invaded cells/well normalized to the respective control is shown. (E) RASV12 transfected FTC-133 cells show increased BrdU incorporation, but direct CLAUDIN-1 modulation by siRNA or Cld1-NLS transfection shows no effect on BrdU incorporation, suggesting that the RASV12 effect is mediated by other signalling pathways than CLAUDIN-1. The percentage of cells with BrDU incorporation normalized to the respective control is shown. Data are represented as mean \pm s.E.M., $n=3-6$, $t$-test, $* P<0.05, * * P<0.01$ and $* * * P<0.001$.

only transwell migration was investigated in the subsequent studies. Thus, faster cell migration was found for Cld1-NLS transfected FTC-133 cells compared to the control in the transwell migration assay (Fig. 3C). Furthermore, in the transwell invasion assay the FTC-133+Cld1NLS cells were more invasive, whereas CLAUDIN-1 siRNA transfected FTC-238 cells were less invasive than the respective control (Fig. 3D). Interestingly, BrdU incorporation was not different in either the Cld1-NLS transfected FTC-133 cells or the CLAUDIN-1 siRNA transfected FTC-238 cells as compared to the respective controls (Fig. 3E).

\section{Positive correlation of CLAUDIN-1 and phosphoprotein kinase $\mathrm{C}$ expression in follicular thyroid carcinoma cells}

To investigate which molecular mechanism or signal transduction pathways could be involved in CLAUDIN-1

Published by Bioscientifica Ltd. 
regulation in human follicular thyroid carcinoma, protein expression patterns of phospho-AKT (pAKT), phosphoERK1/2 (pERK1/2), phosphoPKC (pPKC) and total PKC were determined in CLAUDIN-1 knock-down FTC-238 cells and compared to protein expression of FTC-238 cells transfected with non-targeting control siRNA by western blot analysis. Neither protein expression of pAKT nor protein expression of pERK1/2 was altered between claudin-1 knock-down FTC-238 cells and the control (Fig. 4A). However, western blot analysis revealed a 25-32\% decreased pPKC expression in CLAUDIN-1 siRNA transfected FTC-238 cells as compared to the control either normalized to total PKC expression or the respective loading control (Fig. 4A). The PKC antibodies for total PKC and pPKC used in this study detect several PKC isoforms.
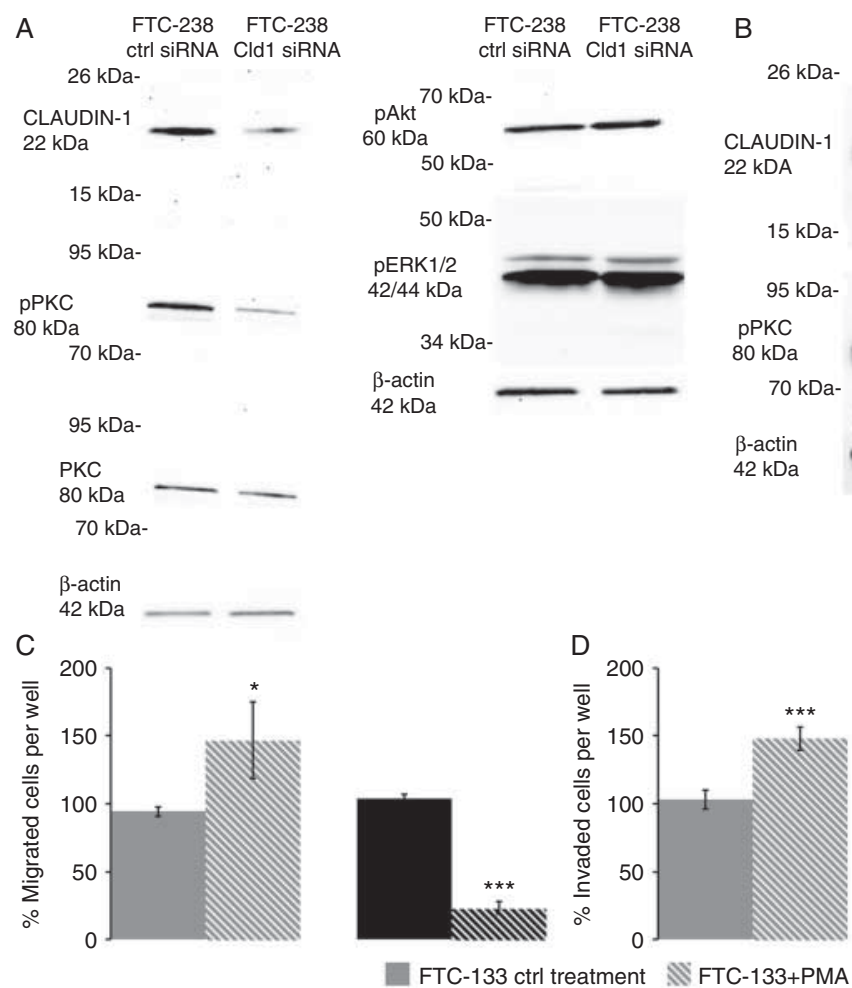

\section{Figure 4}

CLAUDIN-1 and phosphoprotein kinase C expression are correlated in follicular thyroid carcinoma cells. (A) Protein expression of phosphoprotein kinase C (pPKC), total PKC, phospho-AKT (pAKT) and phospho-ERK 1/2 (pERK1/2) in CLAUDIN-1 (Cld1) siRNA and control (ctrl) siRNA transfected FTC-238 cells. Diminished pPKC ( $80 \mathrm{kDa}$ ) expression in FTC-238 + Cld1 siRNA cells as compared to FTC-238+ctrl siRNA cells. No change in protein expression between ctrl siRNA and Cld1 siRNA transfected FTC-238 cells for pAKT $(60 \mathrm{kDa})$ and pERK1/2 (42/44 kDa). (B) Successful pPKC modulation by phorbol-12-myristate-13-acetate (PMA) and Gö6983. PKC activation increases CLAUDIN-1 (22 kDa) protein expression in FTC-133 cells, whereas PKC inhibition decreases CLAUDIN-1 protein expression in FTC-238 cells to
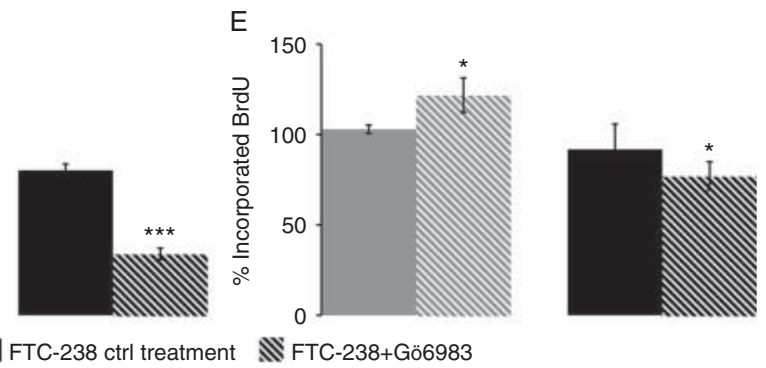

As a next step, endogenous pPKC expression was investigated by western blot in the two follicular thyroid carcinoma cell lines (Fig. 4B). We found a 55\% higher pPKC protein expression in FTC-238 as compared to FTC133 cells. To determine if PKC activation or inhibition influences CLAUDIN-1 expression, FTC-133 and FTC-238 cells were either treated with the PKC activator PMA or the PKC inhibitor Gö6983. Successful PKC activation and inhibition were demonstrated by $45 \%$ increased and $38 \%$ decreased pPKC protein levels, respectively (Fig. 4B). PKC activation of FTC-133 cells resulted in $45 \%$ increased CLAUDIN-1 expression, whereas inhibition of PKC showed a 30\% decreased CLAUDIN-1 expression as compared to the respective control (Fig. 4B).

FTC-133 + PMA cells revealed a faster cell migration, whereas FTC-238+Gö6983 cells showed a slower cell

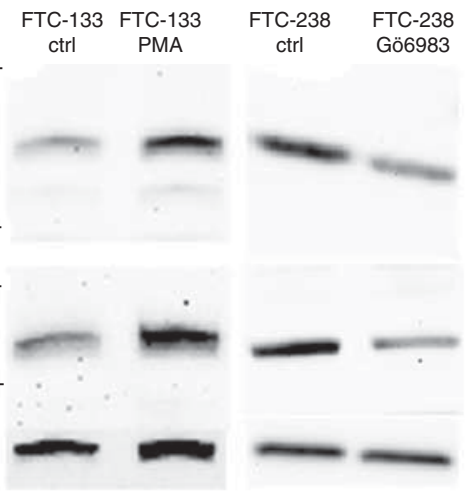

FTC-238 ctrl treatment $\mathbb{N}$ FTC-238+Gö6983 the respective control. $\beta$-actin $(42 \mathrm{kDa})$ was used as a loading control. (C-D) FTC-133 + PMA cells show faster cell migration and invasion as compared to the control. FTC-238+Gö6983 cells reveal a slower cell migration and invasion as compared to the control. The percentage of migrated or invaded cells/well normalized to the respective control is shown. (E) FTC-133 + PMA cells show a faster proliferation rate, whereas FTC-238+Gö6983 cells reveal a reduced cell proliferation compared to controls. The percentage of cell proliferation normalized to the respective control is shown. Data are represented as mean \pm S.E.M., $n=3-4, t$-test, $* P<0.05$ and $* * * P<0.001$.

Published by Bioscientifica Ltd. 
migration than the respective control (Fig. 4C). In addition, in the transwell invasion assay, pharmacological PKC activation in FTC-133 cells resulted in a higher invasion rate and PKC inhibition in FTC-238 cells diminished the transwell invasion rate (Fig. 4D). In the same manner, cell proliferation was increased by PMA treatment of FTC-133 and decreased by Gö6983 treatment of FTC-238 cells resulting in a higher or lower percentage of cells incorporating BrdU compared to the control (Fig. 4E).

\section{Discussion}

CLAUDIN-1 expression is altered in several human malignancies (Resnick et al. 2005, Tokes et al. 2005, Chao et al. 2009) and subcellular expression of CLAUDIN-1 has been linked with tumour invasiveness and an advanced tumour stage (Dhawan et al. 2005, Kinugasa et al. 2012, Eftang et al. 2013). We asked whether CLAUDIN-1 is relevant for the biological behaviour of human follicular thyroid cancer. Our study confirms CLAUDIN-1 expression in human thyroid tissues and shows a shift to subcellular CLAUDIN-1 localization in follicular thyroid tumours and nuclear CLAUDIN-1 expression in FTC metastases. These findings are in contrast to two previous reports on CLAUDIN-1 in thyroid cancer. Very low or nearly absent CLAUDIN-1 expression has been observed in human follicular thyroid tumours by immunohistochemistry in one study, while another study found weak CLAUDIN-1 expression in human follicular adenoma and FTC tissues (Nemeth et al. 2010) and postulated that low CLAUDIN-1 expression correlates with tumour de-differentiation (Tzelepi et al. 2008).

Technical or experimental differences as well as different selections of patients in our study may account for these discrepant findings. One shortcoming of this study is that data on clinical courses of our FTC patients are lacking. On the other hand, we clearly show a shift of CLAUDIN-1 expression with a more pronounced nuclear CLAUDIN-1 localization in FTC metastases.

To explore these first findings on immunohistochemistry, we employed two FTC cell lines as in vitro models of follicular thyroid cancer. In cell culture, we could confirm the more aggressive behaviour of FTC-238 cells by a faster scratch closing, higher migration and invasion rates (Hoelting et al. 1994) and a higher proliferation rate as compared to FTC-133 cells. Both cell lines, FTC-133 and FTC-238, were found to express nuclear localized CLAUDIN-1, yet a higher protein expression was demonstrated in the more aggressive FTC-238 cells. Translocation of CLAUDIN-1 from the cell membrane to subcellular compartments has been described in different human tumours and has been associated with the tumourigenicity of cancer cells (Miwa et al. 2001). In addition, loss of membranous tight junction proteins could negatively influence cell cohesion and/or cell differentiation (Ding et al. 2013). Moreover, in colon cancer, nuclear CLAUDIN-1 localization has been linked to cellular and metastatic behaviour (Dhawan et al. 2005). The molecular mechanism involved in the internalization of CLAUDIN-1 into subcellular or nuclear compartments is hypothesized to be regulated by post-translational modifications like phosphorylation (D'Souza et al. 2005), mutations (Dhawan et al. 2005) and/or promoter gene hypermethylation (Boireau et al. 2007). The increase in nuclear CLAUDIN-1 expression during scratch induction could reflect enhanced migration in close proximity of the scratch, because it has been suggested that CLAUDIN proteins translocate from the cell surface to intracellular compartments at the site where cell migration occurs (Takehara et al. 2009). In our cell models, CLAUDIN-1 is already localized in the cell nucleus and only shows an enriched nuclear expression around the scratch in FTC cell lines.

Furthermore, we observed that CLAUDIN-1 expression is increased in FTC-133 cells by transient transfection of $H$-RASV12. Mutations in one of the three $R A S$ genes $\left(N_{-}, \mathrm{K}-, \mathrm{H}-\mathrm{RAS}\right)$ are frequently observed in human carcinomas (Takashima \& Faller 2013). In addition, the RASV12 mutation is a well-known molecular alteration in FTC leading to constitutive activation of RAS-mediated signalling pathways (Theoharis etal. 2012). It can thus be suggested that the elevated pathogenic character of RASV12 transfected FTC-133 cells involves the increase of CLAUDIN-1 protein expression. This increase in CLAUDIN-1 expression after RASV12 transfection was also observed in normal renal epithelial cells, whereby in these normal cells CLAUDIN-1 was localized in the cell membrane (Mullin et al. 2005). As a side note, we tried CLAUDIN-1 downregulation by CLAUDIN-1 siRNA transfection of RASV12 transfected FTC-133 cells, which resulted in cell death within a few hours, potentially due to the augmented stress of cells, and irrespective if cells were transfected either with control siRNA or CLAUDIN-1 siRNA transfection mixture (unpublished observation). However, RASV12 transfection in FTC-133 cells not only resulted in an increased CLAUDIN-1 expression but also showed faster migration, invasion and proliferation rates. This indirectly suggests a regulatory function of subcellular CLAUDIN-1 expression in the biological behaviour of FTC cells.

Published by Bioscientifica Ltd. 
As a proof of the relevance of nuclear CLAUDIN-1 in the biological behaviour of FTC cell lines, the nuclear CLAUDIN-1 protein amount was modulated, i.e., elevated by CLAUDIN-1-NLS transfection of FTC-133 cells or reduced by CLAUDIN-1 siRNA transfection of FTC-238 cells. Increased nuclear CLAUDIN-1 expression in FTC-133 cells augmented cell migration and invasion; however, effects were less pronounced than in FTC-133+RASV12 cells. These differences could be, on the one hand, explained by the high oncogenic potential of RASV12 (Saavedra et al. 2000). On the other hand, CLAUDIN-1 could be predominantly associated with FTC motility leading to a promotion of metastases. Interestingly, cell proliferation of FTC-133 cells is not altered by CLAUDIN-1NLS transfection. CLAUDIN-1 knock-down in FTC-238 cells by CLAUDIN-1 siRNA leads to opposite results with lower migration and invasion rates as compared to nontargeting siRNA transfection. The slight decrease in the scratch closing capacity of FTC-238 cells by transfection of non-targeting siRNA could be explained by non-specific influences of the scrambled sequence within the cellular mRNA of FTC-238 cells and re-emphasizes the necessity for adequate controls. Similarly to CLAUDIN-1-NLS transfected FTC-133 cells, cell proliferation is not influenced in CLAUDIN-1 knock-down cells. In melanoma cells, an increase of nuclear CLAUDIN-1 by transfection of CLAUDIN-1-NLS also showed no changes in cell proliferation as compared to EV control cells (French et al. 2009). Therefore, it could be speculated that CLAUDIN-1 influences the tumorigenic behaviour of FTC cells but does not affect proliferative activity.

The role of PKC has previously been studied in relation to thyroid tumourigenesis and thyroid cancer (Hoelting et al. 1997, Knauf et al. 2002, Mole et al. 2012). In FTC-133 cells, PKC activation by PMA increased cell invasion (Hoelting et al. 1997). Others, however, have found a negative correlation between PKC activation and cell proliferation in human thyroid cancer cells (Koike et al. 2006, Afrasiabi et al. 2008). In our study we found a higher pPKC protein expression in FTC-238 compared to FTC-133 cells. In addition, CLAUDIN-1 knock-down resulted in a decrease in pPKC expression in FTC-238 cells. In melanoma, a CLAUDIN-1 dependent increase of cell motility has previously been described and was linked to PKC activation (Leotlela et al. 2007). Whether PKC activity also influences CLAUDIN-1 expression in FTC cell lines was further investigated by treatment of FTC cells with either the PKC activator PMA or the PKC inhibitor Gö6983. In this setting we could confirm the study of Hoelting et al. (1997), showing a positive correlation between PKC activity and cell migration and invasion as well as cell proliferation. Moreover, PKC activation by PMA increased CLAUDIN-1 protein expression in FTC-133 cells, whereas PKC inhibition by Gö6983 diminished CLAUDIN-1 protein expression in FTC-238 cells. These results are in line with previous studies of PKC, CLAUDIN-1 interaction in human melanoma cells (Leotlela et al. 2007). The question, which PKC isoform could be involved in CLAUDIN-1 regulation in FTC cell lines, arises. Previous studies in human liver cells showed a correlation between CLAUDIN-1 and PKC delta expression (Yoon et al. 2010). In melanoma cells, an involvement of several PKC isoforms ( $\alpha, \beta$ and $\delta$ isoforms) in CLAUDIN-1 regulation has been reported (Leotlela et al.2007), and furthermore, it was shown that PKC-induced upregulation of CLAUDIN-1 results in the upregulation of the MMP-2 (Leotlela et al. 2007). Interestingly, MMP- 2 expression has also been reported in human FTC tissues (Cho Mar et al. 2006) and, more recently, it was shown that the cellular growth capacity of FTC-133 cells is influenced by MMP-2 activity (Mitmaker et al. 2011). We therefore speculate that MMP-2 could be regulated by CLAUDIN-1 via PKC in FTC. The PKC modulators PMA and Gö6983 used in this study are directed against PKC isoforms $\alpha, \beta, \gamma, \delta$ and $\varepsilon$ (Ryves et al. 1991, Leotlela et al. 2007). It has been shown that FTC-133 cells express PKC isoforms beta II and delta on the protein level (Molé et al. 2010), which may suggest that these isoforms are relevant for CLAUDIN-1 regulation in follicular thyroid cancer. However, further studies need to be conducted to clarify which isoforms of PKC are involved and to which extent PKC, CLAUDIN-1 and MMPs interact. To this end a strategy could involve the use of isoform-selective PKC inhibitors, PKC specific agonist and antagonist peptides (Chang \& Tepperman 2003) and MMP specific inhibitors either alone or in combination with CLAUDIN-1 modulation in FTC cell lines.

In conclusion, CLAUDIN-1 expression and localization is altered in follicular thyroid tumours and FTC metastases. In cell culture experiments modulation of CLAUDIN-1 expression influences the functional behaviour of follicular thyroid carcinoma cells. Furthermore, we provide the first evidence for a role of PKC signalling in regulation of CLAUDIN-1 expression and FTC aggressiveness opening new potential avenues for thyroid cancer targeting.

\section{Declaration of interest}

The authors declare that there is no conflict of interest that could be perceived as prejudicing the impartiality of the research reported.

Published by Bioscientifica Ltd. 


\section{Funding}

This work was supported by D F G FU 356/3-3.

\section{Acknowledgements}

Authors thank Dr K Krause (University Hospital Leipzig, Germany) and PD Dr I E Blasig (FMP Berlin, Germany) for providing us with the RASV12C40 and CLAUDIN-1 plasmids as well as Dr I Bendix (University Hospital Essen, Germany) for support with the confocal microscopy. We are also grateful to $S$ Rehn and A Jaeger for their dedicated technical support.

\section{References}

Afrasiabi E, Ahlgren J, Bergelin N \& Tornquist K 2008 Phorbol 12-myristate 13-acetate inhibits FRO anaplastic human thyroid cancer cell proliferation by inducing cell cycle arrest in $\mathrm{G} 1 / \mathrm{S}$ phase: evidence for an effect mediated by PKCס. Molecular and Cellular Endocrinology 292 26-35. (doi:10.1016/j.mce.2008.04.018)

Ban EJ, Andrabi A, Grodski S, Yeung M, McLean C \& Serpell J 2012 Follicular thyroid cancer: minimally invasive tumours can give rise to metastases. ANZ Journal of Surgery 82 136-139. (doi:10.1111/j.14452197.2011.05979.x)

Boireau S, Buchert M, Samuel MS, Pannequin J, Ryan JL, Choquet A, Chapuis H, Rebillard X, Avances C, Ernst M et al. 2007 DNAmethylation-dependent alterations of claudin-4 expression in human bladder carcinoma. Carcinogenesis 28 246-258. (doi:10.1093/carcin/ bgl120)

Chang Q \& Tepperman BL 2003 Effect of selective PKC isoform activation and inhibition on TNF- $\alpha$-induced injury and apoptosis in human intestinal epithelial cells. British Journal of Pharmacology 140 41-52. (doi:10.1038/sj.bjp.0705398)

Chao YC, Pan SH, Yang SC, Yu SL, Che TF, Lin CW, Tsai MS, Chang GC, Wu CH, Wu YY et al. 2009 Claudin-1 is a metastasis suppressor and correlates with clinical outcome in lung adenocarcinoma. American Journal of Respiratory and Critical Care Medicine 179 123-133. (doi:10.1164/rccm.200803-456OC)

Cho Mar K, Eimoto T, Tateyama H, Arai Y, Fujiyoshi Y \& Hamaguchi M 2006 Expression of matrix metalloproteinases in benign and malignant follicular thyroid lesions. Histopathology 48 286-294. (doi:10.1111/ j.1365-2559.2005.02325.x)

Dhawan P, Singh AB, Deane NG, No Y, Shiou SR, Schmidt C, Neff J, Washington MK \& Beauchamp RD 2005 Claudin-1 regulates cellular transformation and metastatic behavior in colon cancer. Journal of Clinical Investigation 115 1765-1776. (doi:10.1172/JCI24543)

Ding L, Lu Z, Lu Q \& Chen YH 2013 The claudin family of proteins in human malignancy: a clinical perspective. Cancer Management and Research 5 367-375. (doi:10.2147/CMAR.S38294)

D'Souza T, Agarwal R \& Morin PJ 2005 Phosphorylation of claudin-3 at threonine 192 by cAMP-dependent protein kinase regulates tight junction barrier function in ovarian cancer cells. Journal of Biological Chemistry 280 26233-26240. (doi:10.1074/jbc.M502003200)

Eftang LL, Esbensen Y, Tannaes TM, Blom GP, Bukholm IR \& Bukholm G 2013 Up-regulation of CLDN1 in gastric cancer is correlated with reduced survival. BMC Cancer 13 586. (doi:10.1186/1471-2407-13-586)

French AD, Fiori JL, Camilli TC, Leotlela PD, O'Connell MP, Frank BP, Subaran S, Indig FE, Taub DD \& Weeraratna AT 2009 PKC and PKA phosphorylation affect the subcellular localization of claudin-1 in melanoma cells. International Journal of Medical Sciences 6 93-101. (doi:10.7150/ijms.6.93)

Geback T, Schulz MM, Koumoutsakos P \& Detmar M 2009 TScratch: a novel and simple software tool for automated analysis of monolayer wound healing assays. Biotechniques 46 265-274. (doi:10.2144/000113083)
Gonzalez-Mariscal L, Betanzos A, Nava P \& Jaramillo BE 2003 Tight junction proteins. Progress in Biophysics and Molecular Biology 81 1-44. (doi:10.1016/S0079-6107(02)00037-8)

Hoelting T, Siperstein AE, Clark OH \& Duh QY 1994 Epidermal growth factor enhances proliferation, migration, and invasion of follicular and papillary thyroid cancer in vitro and in vivo. Journal of Clinical Endocrinology and Metabolism 79 401-408. (doi:10.1210/jcem.79.2. 8045955)

Hoelting T, Duh QY, Clark OH \& Herfarth C 1997 Invasion of metastatic human follicular thyroid cancer is inhibited via antagonism of protein kinase C. Cancer Letters 119 1-5. (doi:10.1016/S0304-3835(97)00242-5)

Kinugasa T, Akagi Y, Ochi T, Tanaka N, Kawahara A, Ishibashi Y, Gotanda Y, Yamaguchi K, Shiratuchi I, Oka Y et al. 2012 Increased claudin-1 protein expression in hepatic metastatic lesions of colorectal cancer. Anticancer Research 32 2309-2314.

Knauf JA, Ward LS, Nikiforov YE, Nikiforova M, Puxeddu E, Medvedovic M, Liron T, Mochly-Rosen D \& Fagin JA 2002 Isozyme-specific abnormalities of PKC in thyroid cancer: evidence for post-transcriptional changes in PKC $\varepsilon$. Journal of Clinical Endocrinology and Metabolism 87 2150-2159. (doi:10.1210/jcem.87.5.8441)

Koike K, Fujii T, Nakamura AM, Yokoyama G, Yamana H, Kuwano M \& Shirouzu K 2006 Activation of protein kinase $C \delta$ induces growth arrest in NPA thyroid cancer cells through extracellular signal-regulated kinase mitogen-activated protein kinase. Thyroid 16 333-341. (doi:10.1089/thy.2006.16.333)

Leotlela PD, Wade MS, Duray PH, Rhode MJ, Brown HF, Rosenthal DT, Dissanayake SK, Earley R, Indig FE, Nickoloff BJ et al. 2007 Claudin-1 overexpression in melanoma is regulated by PKC and contributes to melanoma cell motility. Oncogene 26 3846-3856. (doi:10.1038/sj.onc. 1210155)

McIver B, Grebe SK \& Eberhardt NL 2004 The PAX8/PPAR $\gamma$ fusion oncogene as a potential therapeutic target in follicular thyroid carcinoma. Current Drug Targets. Immune, Endocrine and Metabolic Disorders 4 221-234. (doi:10.2174/1568008043339802)

Mitmaker EJ, Griff NJ, Grogan RH, Sarkar R, Kebebew E, Duh QY, Clark OH \& Shen WT 2011 Modulation of matrix metalloproteinase activity in human thyroid cancer cell lines using demethylating agents and histone deacetylase inhibitors. Surgery 149 504-511. (doi:10.1016/j. surg.2010.10.007)

Miwa N, Furuse M, Tsukita S, Niikawa N, Nakamura Y \& Furukawa Y 2001 Involvement of claudin- 1 in the $\beta$-catenin/Tcf signaling pathway and its frequent upregulation in human colorectal cancers. Oncology Research 12 469-476. (doi:10.3727/096504001108747477)

Molé D, Minoia M, Tagliati F, Zatelli MC \& degli Uberti EC 2010 Evaluation of PKC isoforms expression in thyroid cells lines and effects of a PKC beta II selective inhibitor. Endocrine Abstracts 22 P764. (available at: http://www.endocrine-abstracts.org/ea/0022/ea0022p764.htm)

Mole D, Gentilin E, Gagliano T, Tagliati F, Bondanelli M, Pelizzo MR, Rossi M, Filieri C, Pansini G, degli Uberti EC et al. 2012 Protein kinase C: a putative new target for the control of human medullary thyroid carcinoma cell proliferation in vitro. Endocrinology 153 2088-2098. (doi:10.1210/en.2011-1988)

Mullin JM, Leatherman JM, Valenzano MC, Huerta ER, Verrechio J, Smith DM, Snetselaar K, Liu M, Francis MK \& Sell C 2005 Ras mutation impairs epithelial barrier function to a wide range of nonelectrolytes. Molecular Biology of the Cell 16 5538-5550. (doi:10.1091/mbc.E0504-0294)

Muresan MM, Olivier P, Leclere J, Sirveaux F, Brunaud L, Klein M, Zarnegar R \& Weryha G 2008 Bone metastases from differentiated thyroid carcinoma. Endocrine-Related Cancer 15 37-49. (doi:10.1677/ ERC-07-0229)

Nemeth J, Nemeth Z, Tatrai P, Peter I, Somoracz A, Szasz AM, Kiss A \& Schaff Z 2010 High expression of claudin-1 protein in papillary thyroid tumor and its regional lymph node metastasis. Pathology Oncology Research 16 19-27. (doi:10.1007/s12253-009-9182-9) 
Resnick MB, Konkin T, Routhier J, Sabo E \& Pricolo VE 2005 Claudin-1 is a strong prognostic indicator in stage II colonic cancer: a tissue microarray study. Modern Pathology 18 511-518. (doi:10.1038/modpathol.3800301)

Ryves WJ, Evans AT, Olivier AR, Parker PJ \& Evans FJ 1991 Activation of the PKC-isotypes $\alpha, \beta 1, \gamma, \delta$ and $\varepsilon$ by phorbol esters of different biological activities. FEBS Letters 288 5-9. (doi:10.1016/0014-5793 (91)80989-G)

Saavedra HI, Knauf JA, Shirokawa JM, Wang J, Ouyang B, Elisei R, Stambrook PJ \& Fagin JA 2000 The RAS oncogene induces genomic instability in thyroid PCCL3 cells via the MAPK pathway. Oncogene 19 3948-3954. (doi:10.1038/sj.onc.1203723)

Saiselet M, Floor S, Tarabichi M, Dom G, Hebrant A, van Staveren WC \& Maenhaut C 2012 Thyroid cancer cell lines: an overview. Frontiers in Endocrinology 3 133. (doi:10.3389/fendo.2012.00133)

Simon D, Goretzki PE, Gorelev V, Ebling B, Reishaus E, Lyons J, Haubruck H \& Roher HD 1994 Significance of P53 in human thyroid tumors. World Journal of Surgery 18 535-540; discussion 540-531. (doi:10.1007/ BF00353758)

Takashima A \& Faller DV 2013 Targeting the RAS oncogene. Expert Opinion on Therapeutic Targets 17 507-531. (doi:10.1517/14728222.2013. 764990)
Takehara M, Nishimura T, Mima S, Hoshino T \& Mizushima T 2009 Effect of claudin expression on paracellular permeability, migration and invasion of colonic cancer cells. Biological \& Pharmaceutical Bulletin 32 825-831. (doi:10.1248/bpb.32.825)

Theoharis C, Roman S \& Sosa JA 2012 The molecular diagnosis and management of thyroid neoplasms. Current Opinion in Oncology $\mathbf{2 4}$ 35-41. (doi:10.1097/CCO.0b013e32834dcfca)

Tokes AM, Kulka J, Paku S, Szik A, Paska C, Novak PK, Szilak L, Kiss A, Bogi K \& Schaff Z 2005 Claudin-1, -3 and -4 proteins and mRNA expression in benign and malignant breast lesions: a research study. Breast Cancer Research 7 R296-R305. (doi:10.1186/bcr983)

Tzelepi VN, Tsamandas AC, Vlotinou HD, Vagianos CE \& Scopa CD 2008 Tight junctions in thyroid carcinogenesis: diverse expression of claudin-1, claudin-4, claudin-7 and occludin in thyroid neoplasms. Modern Pathology 21 22-30. (doi:10.1038/modpathol. 3800959)

Yoon CH, Kim MJ, Park MJ, Park IC, Hwang SG, An S, Choi YH, Yoon G \& Lee SJ 2010 Claudin-1 acts through c-Abl-protein kinase C $\delta$ (PKC $\delta$ ) signaling and has a causal role in the acquisition of invasive capacity in human liver cells. Journal of Biological Chemistry 285 226-233. (doi:10.1074/jbc.M109.054189)

Received in final form 21 July 2015

Accepted 28 July 2015

Made available online as an Accepted Preprint

28 July 2015
(C) 2015 Society for Endocrinology Printed in Great Britain
Published by Bioscientifica Ltd. 